\title{
First experience with Remote Sensing methods and selected sensors in the monitoring of mining areas - a case study of the Belchatow open cast mine
}

\author{
Jaroslaw Wajs s,* $^{1, *}$ \\ ${ }^{1}$ Wroclaw University of Science and Technology, Faculty of Geoengineering, Mining and Geology, \\ 27 Wyb. Wyspianskiego St., 50-370 Wroclaw, Poland
}

\begin{abstract}
The paper presents satellite imagery from active SENTINEL$1 \mathrm{~A}$ and passive SENTINEL-2A/2B sensors for their application in the monitoring of mining areas focused on detecting land changes. Multispectral scenes of SENTINEL-2A/2B have allowed for detecting changes in land-cover near the region of interest (ROI), i.e. the Szczercow dumping site in the Belchatow open cast lignite mine, central Poland, Europe. Scenes from SENTINEL-1A/1B satellite have also been used in the research. Processing of the SLC signal enabled creating a return intensity map in VV polarization. The obtained SAR scene was reclassified and shows a strong return signal from the dumping site and the open pit. This fact may be used in detection and monitoring of changes occurring within the analysed engineering objects.
\end{abstract}

\section{Introduction}

Monitoring of mining areas with application of geodetic measurements is the basic task of mining surveys. Classical geodetic measurements include linear probing of the terrain by observation lines, and surface probing such as measurement with use of a regular grid within the surveyed mining area [1]. Classical observation systems in open cast mines use surface, photogrammetric and satellite GNSS geodetic measurements as a source of input data for GIS 3D databases [2]. The paper presents selected applications of satellite remote sensing in the monitoring of mining areas and their surroundings with regard to assessing the influence of open cast mining on the environment $[3,4]$. Issues of remote sensing monitoring are presented in macro scale [5]. The processed remote sensed data have allowed for large-surface analysis as a tool for identifying local anomalies and identification of potential hazards [6].

\footnotetext{
* Corresponding author: jaroslaw.wajs@pwr.edu.pl
} 


\section{Motivation}

Being the member of the European Space Agency since 2012, Poland has become a beneficiary of the Copernicus programme, which continues the European GMESS programme. Products of satellite images in the Copernicus programme allow for acquisition of high-resolution radiometric, spatial and temporal remote sensing data. The paper analyses scenes from passive sensors SENTINEL-2A and 2B. A subsequent part of the research were scenes from active sensors SENTINEL-1A and 1B. The present state of sensor development for 2016 was presented by Toth et al. [7], and the chances and challenges for future years were discussed by Ban [8].

\section{Study area}

The analyses were performed in the PGE GiEK KWB Belchatow open pit lignite mine located in central Poland, Europe. The KWB Belchatow object comprises two excavation areas. The first exploited area was the Belchatow exposure, marked with an A in Fig. 1. The outline of the open pit and of the internal dumping site is marked with a black rectangle. Letter B marks the Szczercow excavation. Letters D and E depict areas representing the exploited lignite deposit. The ROI included the Szczercow external dumping site and is marked with a white square and the letter E.

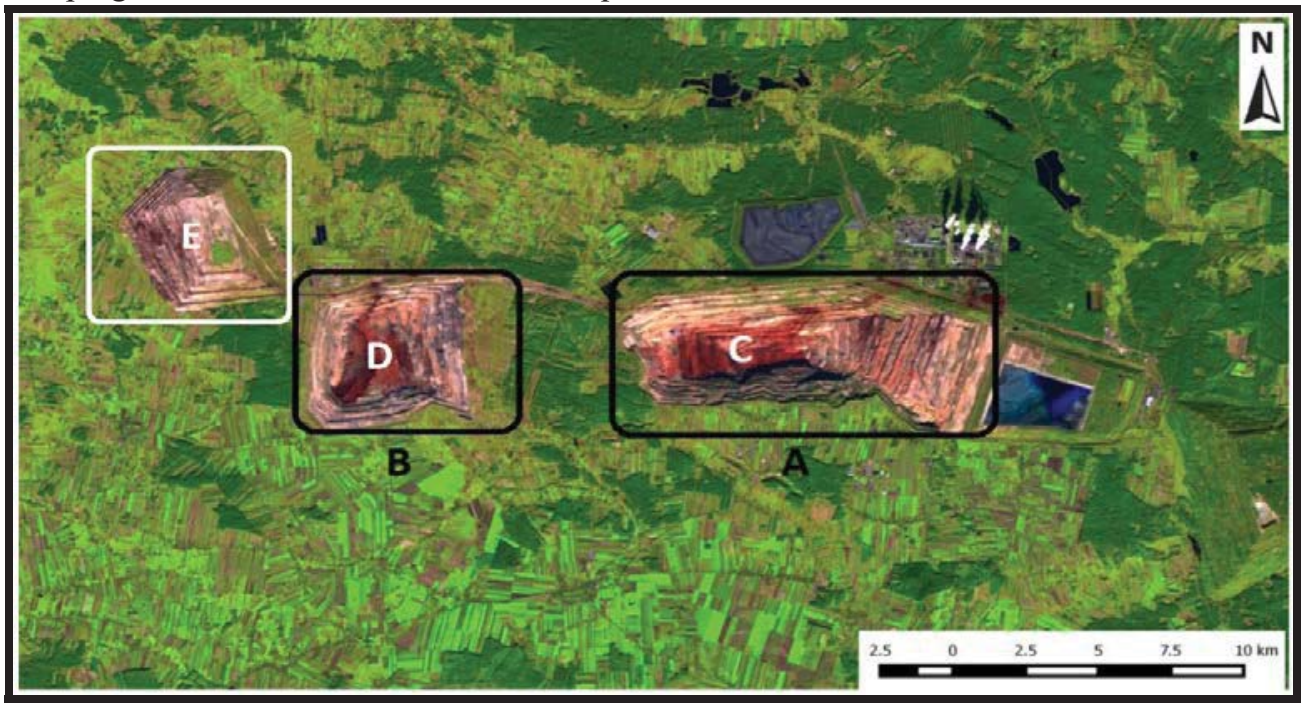

Fig. 1. Portion of Landsat 8 scene of the Belchatow open pit lignite mine. The combination is in a false colour 6-5-4 band acquired on 24th August 2014.

\section{Methodology}

The methodology of data analysis was based on the study of available remote sensing sensors for ROI analyses. A subsequent stage was the elaboration of the processing path of SENTINEL-2 and SENTINEL-1 data. The research included selecting algorithms, tools, data processing and spectral classification focused on detection of changes within the analyzed Szczerców dumping area. 


\subsection{Analysed Remote Sensing sensors}

The first part of the research focused on the overview of remote sensing sensors used for the analysis. Data presented in Table 1 were classified with regard to type of sensor, spatial and temporal resolution, return time, and application for monitoring of mining areas. The data indicate that RapidEye observation system have the best field resolution, reaching $5 \mathrm{~m}$ on the equator. Rapideye imagery may thus become a competition for SENTINEL-2 MSI scenes. SENTINEL-2 is a European wide-swath, high-resolution, multispectral operational imaging mission within the GMES (Global Monitoring for Environment and Security) programme, jointly implemented by the EC (European Commission) and ESA (European Space Agency) for global land observation. It was launched on $23^{\text {rd }}$ June 2015 and the first imagery of ROI was acquired in August 2016. The full mission specification of the twin satellites flying in the same orbit but phased at $180^{\circ}$, is designed to give a high revisit frequency of 5 days at the equator. The twin satellites of SENTINEL-2 provide a continuity of USGS services: SPOT and LANDSAT imagery datasets science 1972. SENTINEL-2 carries out a Multi-Spectral Optical Instrument payload that samples 13 spectral bands: four bands at $10 \mathrm{~m}$, six bands at $20 \mathrm{~m}$ and three bands at $60 \mathrm{~m}$ spatial resolution. The orbital swath width is $290 \mathrm{~km}$. The SENTINEL-2 mission orbit is sun-synchronous, with 143 orbits per cycle for a single satellite. Sun-synchronous orbits are used for consistent maintenance of the angle of sunlight on Earth's surface. SENTINEL-2A and SENTINEL2B occupy the same orbit, but are separated by $180^{\circ}$. The mean orbital altitude is $786 \mathrm{~km}$. The orbit inclination is $98.62^{\circ}$ and the Mean Local Solar Time (MLST) at the descending node is 10:30 (am). This value of MLST was chosen as a compromise between the suitable level of solar illumination and minimization of the potential cloud cover.

The second analyzed sensor is SENTINEL-1, which continues the C-band SAR Earth Observation heritage of ESA's ERS-1, ERS-2 and ENVISAT, and Canada's RADARSAT missions. The satellite is equipped with a C-band Synthetic Aperture Radar (SAR), which acquires the Interferometric Wide Swath mode (IWS): $240 \mathrm{~km}$ swath, $5 \mathrm{~m}$ x $20 \mathrm{~m}$ resolution, and a single-look complex. SENTINEL-1 has a near-polar, sun-synchronous orbit with a 12-day repeat cycle and 175 orbits per cycle for a single satellite. Both SENTINEL-1A and SENTINEL-1B share the same orbit plane with a $180^{\circ}$ orbital phasing difference. With both satellites operating, the mission images the entire Earth every six days.

Table 1. Overview of remote sensing sensors used for the analysis.

\begin{tabular}{|c|c|c|c|c|c|c|c|c|c|}
\hline Name & Funding & Launch & Country & $\begin{array}{c}\text { Constell } \\
\text { ation }\end{array}$ & $\begin{array}{c}\text { Sensor } \\
\text { type }\end{array}$ & $\begin{array}{c}\text { GSD } \\
\text { range } \\
\mathbf{( m )}\end{array}$ & $\begin{array}{c}\text { Swath } \\
\text { width } \\
\mathbf{( k m )}\end{array}$ & $\begin{array}{c}\text { Revisit } \\
\text { time } \\
\text { (day) }\end{array}$ & Access \\
\hline RapidEye & Commercial & 2008 & Germany & $\begin{array}{c}5 \\
\text { satellites }\end{array}$ & 5 MSI & $5 \times 5$ & 77 & $1-5,5$ & Paid \\
\hline Sentinel-1 & ESA & 2014 & $\begin{array}{c}\text { European } \\
\text { Union }\end{array}$ & $\begin{array}{c}\text { Dual } \\
\text { satellites }\end{array}$ & $\begin{array}{c}\text { C-band } \\
\text { SAR }\end{array}$ & $\begin{array}{c}5 \times 5 \\
5 \times 20 \\
25 \times 40\end{array}$ & $\begin{array}{c}85, \\
250,\end{array}$ & 6 & Free \\
\hline Sentinel-2 & ESA & 2015 & $\begin{array}{c}\text { European } \\
\text { Union }\end{array}$ & $\begin{array}{c}\text { Dual } \\
\text { satellites }\end{array}$ & 13 MSI & $\begin{array}{c}10 \times 10 \\
20 \times 20 \\
60 \times 60\end{array}$ & 290 & 5 & Free \\
\hline
\end{tabular}




\subsection{Sentinel 2 MSI data pre-processing}

The first stage of data processing from the SENTINEL-2A/2B remote sensing sensors was acquisition of products from the Copernicus Open Access Hub. SENTINEL-2 data are acquired on 13 spectral bands in the visible and near-infrared (VNIR), and shortwavelength infrared (SWIR) spectra, as shown in Table 2. The SENTINEL-2A satellite delivered its first imagery from space on $29^{\text {th }}$ June 2015 . The first images of ROI were with a cloud cover. Monitoring of the Belchatow open pit mine by SENTINEL-2A began on $25^{\text {th }}$ November 2016. L2C ESA products are post-proceed since 2017. Level-2A products are organized in ortho-rectified tiles of $100 \mathrm{~km} \times 100 \mathrm{~km}$ in UTM WGS84 projections. Data processing includes Scene Classification and Atmospheric Correction applied to Top-OfAtmosphere (TOA) Level-1C orthoimage products. The main output of Level-2A is an orthoimage Bottom-Of-Atmosphere (BOA) product with corrected reflectance. The first scene of the analyzed ROI in the L2C standard was acquired on 29 ${ }^{\text {th }}$ March 2017.

Multispectral imagery acquired by Sentinel 2A (MSI - Multi Spectral Instrument) were used to elaborate colour compositions. Fig. 2 present test colour compositions for the analysed images from $4^{\text {th }}$ November 2017. They were used as input data for further analyses and were the source of data for classifying land use and land cover, and land change monitoring in the analysed Szczercow dumping site. The methodology of land change monitoring was based on the Natural Colour RGB, Colour Infrared and NDVI index (Normalized difference vegetation index) colour compositions.

Table 2. List of SENTINEL-2 spectral bands.

\begin{tabular}{|c|c|c|c|l|}
\hline Band & $\begin{array}{c}\text { Resolution } \\
(\mathbf{m})\end{array}$ & $\begin{array}{c}\text { Central wavelength } \\
(\mathbf{n m})\end{array}$ & $\begin{array}{c}\text { Band width } \\
(\mathbf{n m})\end{array}$ & \multicolumn{1}{|c|}{ Purpose } \\
\hline B01 & 60 & 443 & 20 & Aerosol detection \\
\hline B02 & 10 & 490 & 65 & Blue \\
\hline B03 & 10 & 560 & 35 & Green \\
\hline B04 & 10 & 665 & 30 & Red \\
\hline B05 & 20 & 705 & 15 & Vegetation classification \\
\hline B06 & 20 & 740 & 15 & Vegetation classification \\
\hline B07 & 20 & 783 & 20 & Vegetation classification \\
\hline B08 & 10 & 842 & 115 & Near infrared \\
\hline B08A & 20 & 865 & 20 & Vegetation classification \\
\hline B09 & 60 & 945 & 20 & Water vapour \\
\hline B10 & 60 & 1375 & 30 & Cirrus \\
\hline B11 & 20 & 1610 & 90 & $\begin{array}{l}\text { Snow / ice / cloud } \\
\text { discrimination }\end{array}$ \\
\hline B12 & 20 & 2190 & 180 & $\begin{array}{l}\text { Snow / ice / cloud } \\
\text { discrimination }\end{array}$ \\
\hline
\end{tabular}




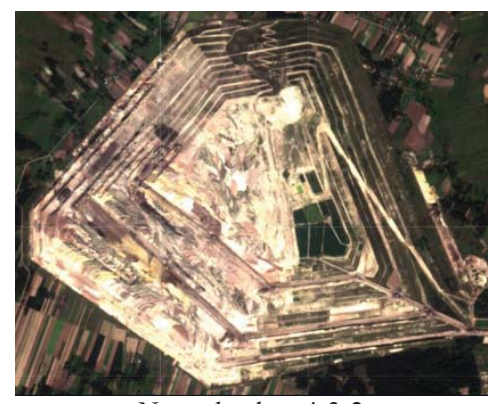

Natural colors 4-3-2

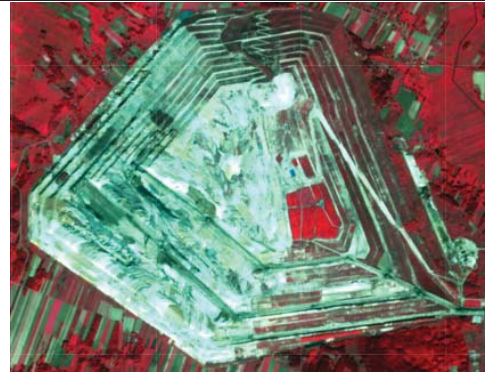

Color infrared (Vegetation) 8-4-3

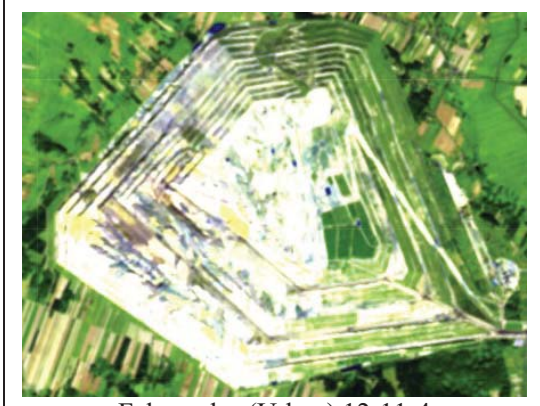

False color (Urban) 12-11-4

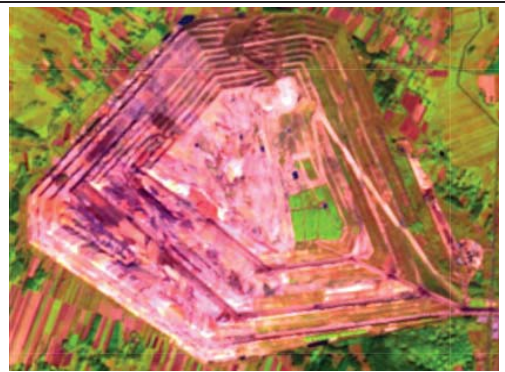

Agriculture 11-8a-2

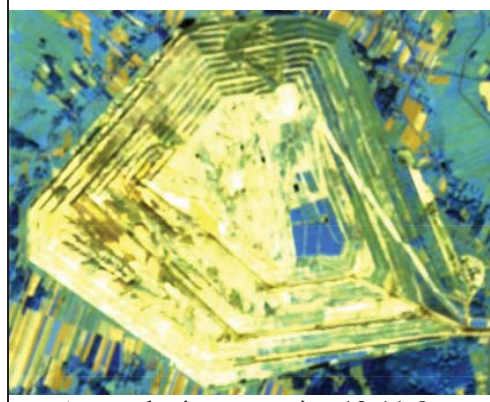

Atmospheric penetration 12-11-8a

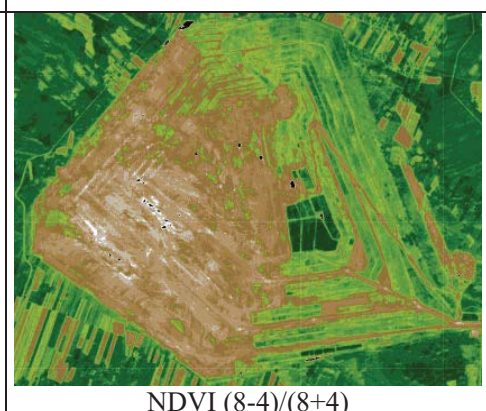

Fig. 2. Example of a selected colour composition of SENTINEL-2A/2B on $4^{\text {th }}$ November 2017.

\subsection{Sentinel 2 MSI change detection}

The procedure of detecting changes based on spectral classification of images was described by Yoshi et al. [9]. The first stage of spectral classification is sub-division of the image into sub-sets; this process is known as segmentation. The main aim of the classification is assignment of the selected segments with similar statistical characteristics and their aggregation into subsets. The classification procedure of remotely sensed imagery leads to select areas with a specific land use and land cover. Detection of changes within the monitored objects requires difference analyses. Based on two temporal states T1 and $\mathrm{T} 2$, change detection is possible for time delta T. In the analyzed ROI, analyses of changes were made using image differencing. The stage of image classification, when potential errors may be summed up in further analyses, was omitted.

Results of the analyses are presented in Fig. 3a-c. The analyses show that application of SENTINEL-2 images allows for obtaining information on land use and land change in the analyzed ROI - Szczercow dumping area. 
Time 1

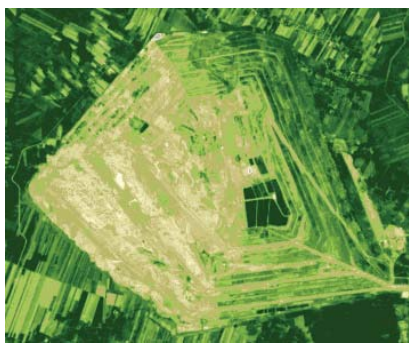

NDVI 2016-08-03

b

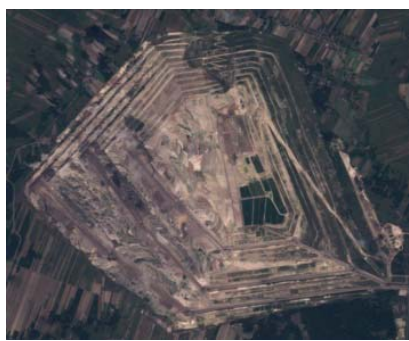

RGB 2016-08-03

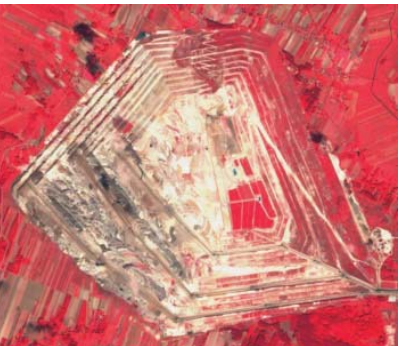

Infrared 2016-08-03
Time 2

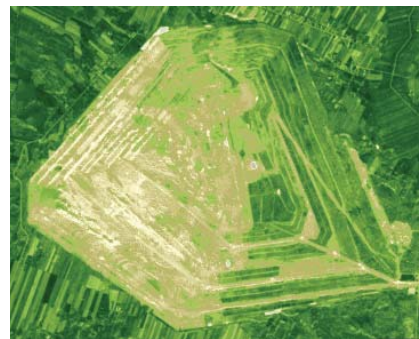

NDVI 2017-11-04

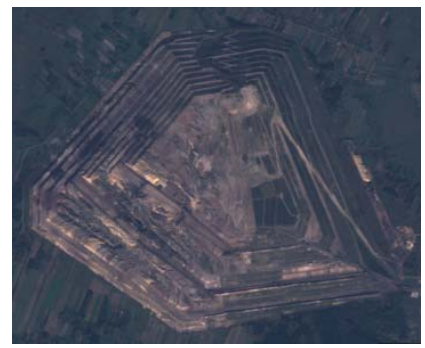

RGB 2017-11-04

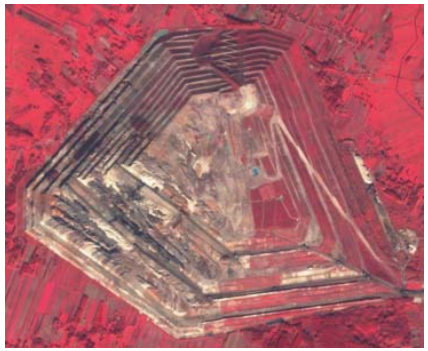

Infrared 2017-11-04
deltaT Change

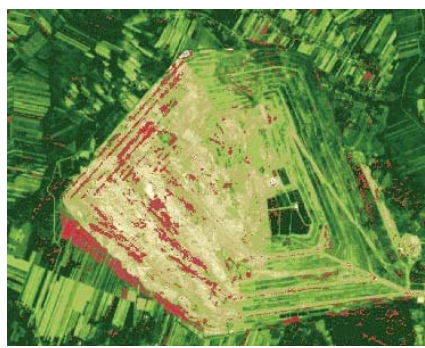

Diff NDVI 2016-08-03/2017-11-04

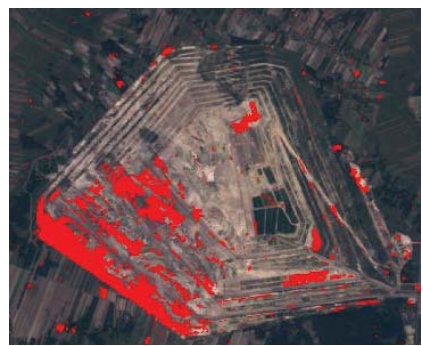

Diff RGB 2016-08-03/2017-11-04

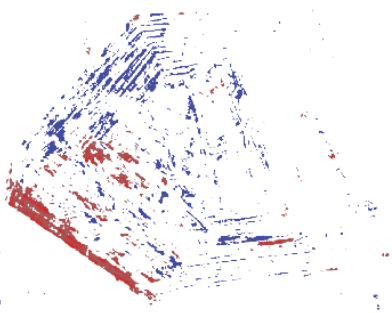

Diff IR 2016-08-03/2017-11-04

Fig. 3. Results of Sentinel 2A change analysis. (a) NDVI spectral band combination, (b) RGB colour combination, (c) Infrared band combination.

\subsection{Synthetic-aperture radar data processing for land classification}

The third part of this report presents analyses of Synthetic Aperture Radar SAR SENTINEL-1A/1B radar images [10]. The analysis focused on a Single Look Complex from SENTINEL-1A in VV polarization from August 2016. Numerous SAR signal processing procedures focus on detection of pseudo vertical changes using pairs of images and difference algorithms (InSAR) $[11,12]$. SAR signal processing was made with the use of the SENTINEL-1 Toolbox (S1TBX) and SENTINEL-2 Toolbox (S2TBX). SNAP is the software platform for the three Sentinel Toolboxes, developed by the European Space Agency (ESA) for exploitation of SENTINEL-1, SENTINEL-2 and SENTINEL-3 missions under GNU GPL open source license. In this report, the SENTINEL-1A scene was cropped to the ROI area, which significantly reduced the processing time. Next, radar image filtration was made with use of Speckle Filtering in the SNAP toolbox. The final image was georeferenced in the WGS 84 system with application of Range Doppler Terrain Correction applications. SLC VV intensity is visualized in Fig. 4. The next stage of SAR imaging was 
its classification controlled by the K-means clustering methodology. Results of this classification are presented in Fig. 5. Blue and yellow colors depict regions characterized by strong return of the radar signal. The image shows that the regions represent industrial areas, buildings and mining areas that are not covered by vegetation. Marked with blue and yellow in Fig. 5, the processed SAR image indicates strong signal return from the dumping site and from the excavation pit of the mine.

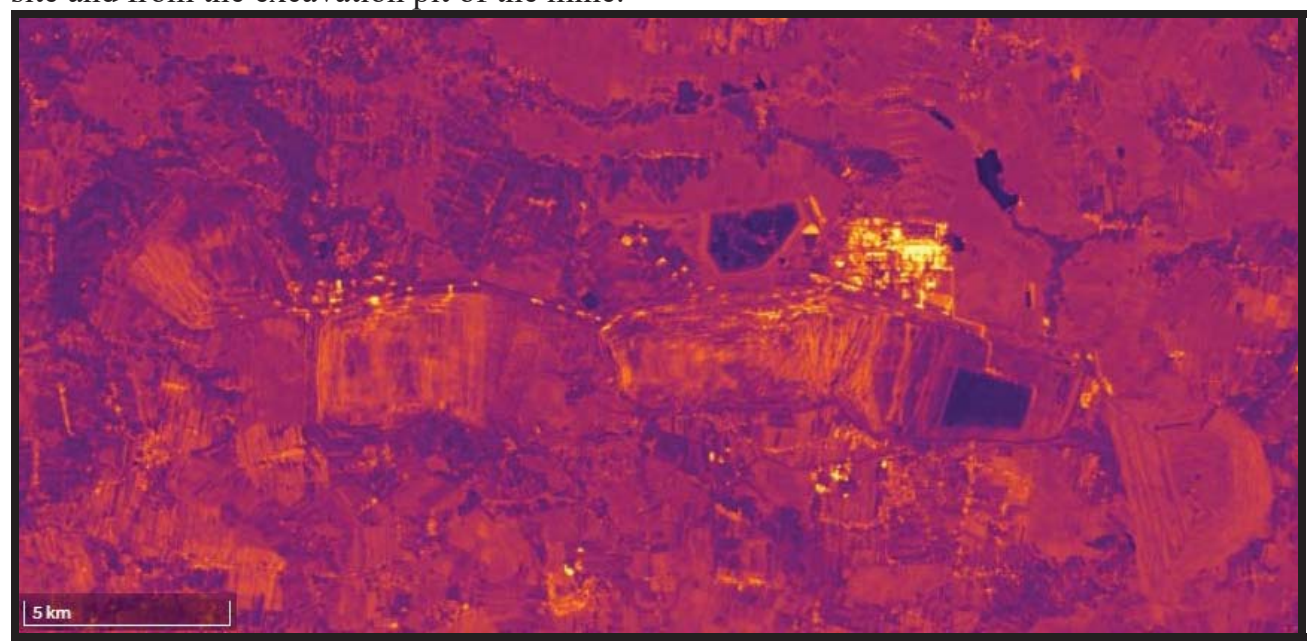

Fig. 4. SENTINEL-1A SLC geometric referenced intensity VV image.

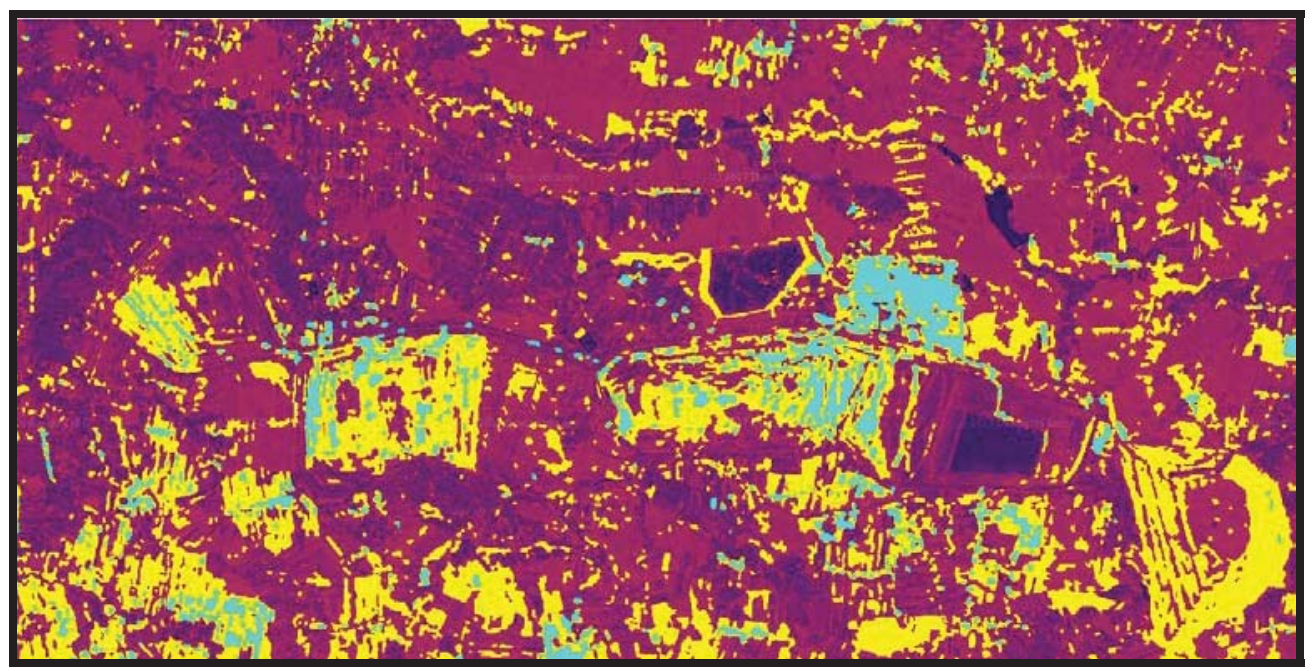

Fig. 5. Sentinel 1A SLC classified intensity VV image.

\section{Results}

Analysed remote sensing imagery allowed to perform large-surface analysis as a tool for detecting local anomalies and identification of potential hazards. Classification of passive scenes allowed for monitoring land use and land change, and determining the changes as $\mathrm{XY}$ components. The data supply information on the area, in which other independent geodetic measurement techniques may be used. The detected changes may induce highresolution techniques for $3 \mathrm{D}$ modelling for obtaining $3 \mathrm{D}$ data. The analysed SAR active 
remote sensing data allowed for monitoring of land use in the Belchatow open cast mine area as an active sensor. These analyses indicate that monitoring of land change and the active state of the open pit mine in macro scale with application of remote sensed imagery is possible. The analyses show that processing of Copernicus SENTINEL scenes with application of numerous revisits above the ROI allows for obtaining reliable information on the actual state of the ROI.

\section{Conclusions}

Results of analysis of SENTINEL-2A/2B passive scenes have allowed for obtaining continuous information in form of raster images with field resolution of $10 \mathrm{~m}$. Spectral analysis of SENTINEL-2A/2B colour compositions enables detection of land change and modelling on XY change in the surrounding of the Belchatow open cast lignite mine. The final product in form of GRID surfaces is a perfect derivative for the GIS database of the mine. Application of data from the SENTINEL-2A/2B passive sensor for the analyzed ROI is a perfect product for terrain analysis in the case, when the area of the open-cast mine is not covered with snow. Another restriction maybe the influence of Earth's atmosphere on the acquisition of MSI images. The presence of clouds significantly decreases the quality and volume of information on multispectral images. Further investigations will use data from HR and VHR imageries from nanosatellites. Contrary to passive remote sensors. SENTINEL-1A/1B active SAR remote sensing is a source of data that are independent from weather conditions, clouds or angle of sunlight. Further investigations on SENTINEL$1 \mathrm{~A} / 1 \mathrm{~B}$ data processing will focus on determining line of sight (LOS) changes in the analyzed area for monitoring of potential pseudo-vertical movements.

This work was financed by the Polish Statutory Research Grant no. 0402/0146/16 and Grant no. 0401/0128/17. Gratitude is expressed to Wojciech Milczarek, PhD Eng., for technical and substantial support during analysis of data from the active SENTINEL-1A/1B sensor.

\section{References}

1. Polish Journal of Laws, pos. 1941 (2015)

2. G. Dawidziak, Z. Skalski, Materiały Sympozjum Warsztaty "Zagrożenia naturalne w górnictwie", Wyd. IGSMiE PAN, Kraków (2004)

3. Z. Kasztelewicz, M. Zajączkowski, Polityka Energetyczna 13, 227-243 (2010)

4. J. Zawadzki, K. Przeździecki, Z. Miatkowski, Journal of environmental management, 166, 605-614 (2016)

5. S. Mularz, W. Drzewiecki, T. Pirowski, Roczniki Geomatyki, T. V, Z. 8 (2007)

6. Z. Miatkowski, S. Lewiński, W. Kowalik, A. Sołtysik, J. Turbiak, Woda Środowisko Obszary Wiejskie 16 (2006)

7. C. Toth, G. Jóźków, ISPRS Journal of Photogrammetry and Remote Sensing, 115, 2236 (2016)

8. Y. Ban, M. Salvatore, E. Lars, International Journal of Remote Sensing, Vol. 38, No. 7, 1759-1764 (2017)

9. N. Joshi, M. Baumann, A. Ehammer, R. Fensholt, K. Grogan, P. Hostert, M. Jepsen, T. Kuemmerle,

P. Meyfroidt, E. Mitchard, J. Reiche, C. Ryan, B. Waske, Remote Sensing, 8(1) (2016) 
10. A. Ferretti, C. Monti-Guarnieri, F. Prati, InSAR Principles: Guidelines for SAR Interferometry Processing and Interpretation (ESA Publications, 2007)

11. T.R. Lauknes, J. Dehls, Y. Larsen, K.A. Høgda, D.J. Weydahl, Fringe 2005 Workshop, Proceedings of the Conference held 28 November - 2 December, 2005 in Frascati, Italy, ESA SP-610 (2006)

12. W. Milczarek, J. Blachowski, P. Grzempowski, Acta Geodyn. Geomater., Vol. 14, No. 1(185), 41-52 (2017) 